\title{
First Year Occupational Therapy Students' Clinical Reasoning Approach to Addressing Challenging Behaviors Related to Sensory Processing Using a Simulated Case Study
}

\author{
Bryan M. Gee \\ Idaho State University \\ Kelly E. Thompson \\ Idaho State University \\ Jane Strickland \\ Idaho State University \\ Lucy Jane Miller \\ STAR institute for Sensory Processing Disorder
}

Follow this and additional works at: https: / encompass.eku.edu/jote

Part of the Occupational Therapy Commons, and the Scholarship of Teaching and Learning Commons

\section{Recommended Citation}

Gee, B. M., Thompson, K. E., Strickland, J., \& Miller, L. J. (2017). First Year Occupational Therapy Students' Clinical Reasoning Approach to Addressing Challenging Behaviors Related to Sensory Processing Using a Simulated Case Study. Journal of Occupational Therapy Education, 1 (2). https://doi.org/10.26681/jote.2017.010207 


\title{
First Year Occupational Therapy Students' Clinical Reasoning Approach to Addressing Challenging Behaviors Related to Sensory Processing Using a Simulated Case Study
}

\begin{abstract}
Occupational therapy students must be prepared to use clinical reasoning to select appropriate interventions for children with sensory processing disorders (SPDs). Although these interventions are typically taught in entry-level occupational therapy programs, there is little information regarding the method by which occupational therapy students are taught a clinical reasoning process to determine which sensory processing intervention to use with pediatric clients. A problem-solving framework called A SECRET was used to teach students clinical reasoning for children with SPDs, via an online, module-based course. Following the module, the students were tested with an online assessment tool regarding their ability to discriminate between appropriate and inappropriate intervention strategies, and to articulate their rationale to demonstrate how they clinically reasoned through a complex client case. Eight students participated in a focus group to provide their perceptions of the online delivery of the content and the A SECRET reasoning process. Five descriptive representations emerged from the qualitative data analysis: the A SECRET Process, Self-Regulation, the Occupational Therapy Practice Framework, Participation, and Safety/Security. The findings suggest an inherent value for online learning to assist occupational therapy students in their program's first year to learn the A SECRET process and then clinically reason through a simulated case study.
\end{abstract}

Keywords

Clinical reasoning, clinical simulation, sensory processing, occupational therapy education

\section{Creative Commons License} (c) (1) (3)

This work is licensed under a Creative Commons Attribution-Noncommercial-No Derivative Works 4.0 License. 


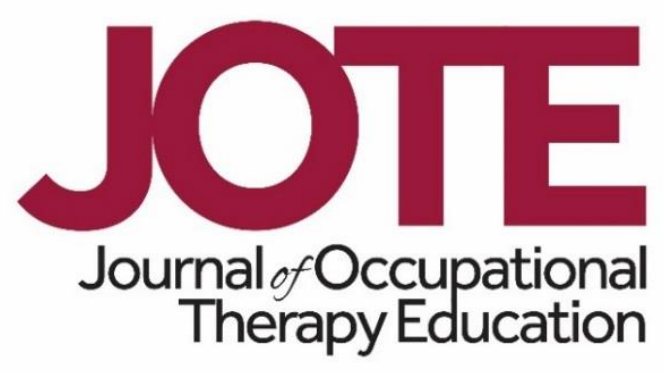

Volume 1, Issue 2

First Year Occupational Therapy Students' Clinical Reasoning Approach to Addressing Challenging Behaviors Related to Sensory Processing Using a Simulated Case Study

\author{
Bryan M. Gee, PhD, MEd, OTR/L, BCP ${ }^{1}$, Kelly E. Thompson, EdD, OTR/L¹, \\ Jane Strickland, EdD ${ }^{1}$, and Lucy Jane Miller, PhD, OTR/L² \\ Idaho State University ${ }^{1}$ and STAR Institute for Sensory Processing Disorder ${ }^{2}$ \\ United States
}

\begin{abstract}
Occupational therapy students must be prepared to use clinical reasoning to select appropriate interventions for children with sensory processing disorders (SPDs). Although these interventions are typically taught in entry-level occupational therapy programs, there is little information regarding the method by which occupational therapy students are taught a clinical reasoning process to determine which sensory processing intervention to use with pediatric clients. A problem-solving framework called A SECRET was used to teach students clinical reasoning for children with SPDs, via an online, module-based course. Following the module, the students were tested with an online assessment tool regarding their ability to discriminate between appropriate and inappropriate intervention strategies, and to articulate their rationale to demonstrate how they clinically reasoned through a complex client case. Eight students participated in a focus group to provide their perceptions of the online delivery of the content and the A SECRET reasoning process. Five descriptive representations emerged from the qualitative data analysis: the A SECRET Process, Self-Regulation, the Occupational Therapy Practice Framework, Participation, and Safety/Security. The findings suggest an inherent value for online learning to assist occupational therapy students in their program's first year to learn the A SECRET process and then clinically reason through a simulated case study.
\end{abstract}

\title{
INTRODUCTION
}

Clinical reasoning skills are essential to quality clinical practice (Rogers, 1983). Clinical reasoning has been defined as the thought process that is used by occupational therapists during evaluation and intervention as part of a therapeutic plan of care (Neistadt, 1996). For occupational therapy students who are learning how to address 
sensory processing deficits in pediatric clients, clinical reasoning is especially important, and can be challenging for educators to teach.

Occupational therapy students must be prepared to provide intervention for children with sensory processing disorders (SPDs). The American Occupational Therapy Association (AOTA) has indicated that $83-90 \%$ of occupational therapists working with pediatric populations provide interventions to address their clients' sensory processing deficits (AOTA, 2010). Green et al. (2006) reported that a sensory processing approach was the third most frequent strategy used in intervention with children with autism spectrum disorder (ASD). It is evident within the literature that a wide array of children demonstrate sensory processing disturbances and that occupational therapists incorporate sensory processing approaches to address those difficulties (Owen et al., 2013; Tomchek, Huebner, \& Dunn, 2014; Wickremasinghe et al., 2013). Therapists use the sensory processing frame of reference (Cole \& Tufano, 2008) to guide evaluation and intervention. There are many types of interventions within this frame of reference available to address sensory processing, including comprehensive intervention (Ayers Sensory Integration Intervention), specialized sensory-based intervention, and sensory motor intervention, making it difficult for students to determine which is best for the client. Although these interventions are typically taught in entry-level occupational therapy programs (Reynolds, Watling, Apletal, \& May-Benson, 2012), there is little information regarding the method by which occupational therapy students are taught a clinical reasoning process to determine which sensory processing intervention to use with a particular pediatric client.

A SECRET (Bailer \& Miller, 2011; Miller, Fuller, \& Roetenberg, 2014) is a problemsolving framework developed for parents/caregivers, teachers, and therapists to enhance problem-solving abilities for their child/client's challenging sensory related behaviors. A SECRET is a mnemonic for (A) Attention, (S) Sensation, (E) Emotional Regulation, (C) Culture/Context/Condition, (R) Relationships, (E) Environment, and (T) Task (see Figure 1). The framework attempts to capture how clinicians think about sensory related behaviors and the questions to ask that may lead to the design and implementation of strategies to reduce duration, frequency, and/or intensity of episodes for a child with SPD (Bailer \& Miller, 2011; Miller et al., 2014). Grounded in the Ecological Model of Sensory Modulation (Miller, Reisman, Mclntosh, \& Simon, 2001), the A SECRET framework targets sensory related behaviors among children who are diagnosed with SPD or have sensory processing difficulties that may comorbidly occur with other medical, behavioral, or developmental conditions (Bailer \& Miller, 2011; Miller et al., 2014). In addition to being a tool for clinicians to determine the most appropriate intervention, A SECRET may be used by educators to teach students a process of clinical reasoning.

Clinical reasoning is a complex concept to teach. Crabtree (1998) characterized clinical reasoning as "the process of how therapists make sense of clinical situations and how they decide to proceed in therapy" (p. 113). Schell and Schell (2008) articulated it as "the process used by practitioners to plan, direct, perform, and reflect upon client care" (p. 5). Higgs and Jones (2008) further stated it is the therapist's ability to take into 
consideration the needs, wishes, and ideals of the client. Finally, Harries and Harries (2001) classified occupational therapists' clinical reasoning as a style of thought content (e.g. procedural), or as reasoning strategies generated through thought processing (hypothetical or deductive). Many forms of clinical reasoning exist within the literature. These include narrative, scientific, diagnostic, procedural, interactive, pragmatic, ethical, and conditional reasoning (Mattingly \& Fleming, 1994; Schell \& Schell, 2008). For the purpose of this article, the seminal work of Mattingly and Fleming (1994) on clinical reasoning among occupational therapy practitioners is used (see Table 1). The variety of definitions and types of clinical reasoning can be overwhelming to students, who may struggle to apply this to a given clinical scenario.

Table 1

Definitions of Clinical Reasoning

\section{Types of Clinical Reasoning in Occupational Therapy}

\begin{tabular}{ll}
\hline $\begin{array}{l}\text { Procedural } \\
\text { Reasoning }\end{array}$ & $\begin{array}{l}\text { Procedural clinical reasoning focuses on the process used to maximize a } \\
\text { client's functioning (Mattingly \& Fleming, 1994); it is the process for solving } \\
\text { problems of daily functioning that occur because of a physical or } \\
\text { psychological condition. }\end{array}$ \\
$\begin{array}{l}\text { Interactive } \\
\text { Reasoning }\end{array}$ & $\begin{array}{l}\text { When a clinician uses interactive clinical reasoning, he or she is seeking } \\
\text { and obtaining information to increase understanding regarding clients' } \\
\text { feelings about themselves and the therapeutic interventions in which they } \\
\text { are currently engaged (Mattingly \& Fleming, 1994). }\end{array}$ \\
Conditional & $\begin{array}{l}\text { Conditional clinical reasoning typically occurs when a therapist is } \\
\text { Reasoning }\end{array}$ \\
$\begin{array}{l}\text { integrating her knowledge of clients' medical, psychological, or } \\
\text { developmental condition and how it relates to functioning in the specific } \\
\text { social and physical contexts on a daily basis (Mattingly \& Fleming, 1994). }\end{array}$ \\
Narrative & $\begin{array}{l}\text { Narrative reasoning emerges during the clinical process as the therapist } \\
\text { and the client collaborate on intervention goals, strategies, and solutions } \\
\text { Reasoning }\end{array}$ \\
\hline
\end{tabular}

Within the occupational therapy literature, several instructional measures to assist students in the development of clinical reasoning have been discussed. The aim of each is to better prepare student practitioners for the diverse challenges of reasoning within routine clinical practice. A review of the literature found use of multimedia (audio, video and/or text) delivered asynchronously online using chat rooms and message boards, and live simulations with students functioning in the role of therapist and/or client in a classroom environment as methods to teach clinical reasoning (Hedge, Pickens, \& Neville, 2015; Lysaght \& Bent, 2005; Neistadt, 1996; Scaffa \& Wooster, 2004). Additional instructional activities designed to promote clinical reasoning in students include interviewing and occupational profile assignments, treatment planning 
assignments, ethical case studies, evidence-based decision-making assignments, and student reflection and journaling assignments (Coker, 2010; Mattingly \& Fleming, 1994; Neistadt, Wight, \& Mulligan, 1998; Peloquin \& Davidson, 1993; Tickle-Degnen, 2000). In addition to didactic course assignments, the completion of up to 24 weeks of clinical affiliations (AOTA, 2012) immerses students in opportunities to hone clinical reasoning skills. Despite the wide-ranging methods for teaching clinical reasoning skills, none were found in the literature specifically focused on teaching occupational therapy students how to determine the best intervention for children with ASD or SPDs.

The literature revealed some support for the use of online instructional delivery to facilitate or enhance existing clinical reasoning among occupational therapy students during fulltime clinical rotations after the completion of their didactic course work (Creel, 2001; Murphy, 2004; Scanlan \& Hancock, 2010, Thomas \& Storr, 2005; Trujillo \& Painter, 2009; Wooster, 2004). The study conducted by Scanlan and Hancock (2010) explored online synchronous and asynchronous interaction of students completing clinical rotations, and reported that the participants demonstrated increased depth in clinical reasoning (procedural reasoning), understanding of the diagnostic presentation of clients (procedural or scientific reasoning), problem solving client cases, and implementation of occupational therapy interventions. However, the occupational therapy literature is silent on two fronts. First, there is little information about the use of online learning to assist students in the development and application of clinical reasoning via simulation. Second, there is minimal information about using an online learning delivery method to teach occupational therapy students the process and application of the A SECRET approach.

The purpose of this article is to describe the perceptions of first year Masters of Occupational Therapy (MOT) students following completion of a novel educational approach to clinical reasoning. This article focuses on the descriptive qualitative analysis of a larger educational case study, published elsewhere (Gee, 2015; Gee, Strickland, Thompson, \& Miller, 2017; Gee, Thompson, Strickland, \& Miller, 2017). In the study, students voluntarily participated in an online, module-based course covering the A SECRET reasoning process (Miller et al., 2014). Following the module, the students were asked to view a video of a child displaying challenging behaviors attributed to sensory processing disturbances. The students were tested via an online assessment tool regarding their ability to discriminate between appropriate and inappropriate intervention strategies. In addition to an objective score, the researchers collected data regarding the students' ability to articulate their reasons for choosing the answers that they gave. Their responses yielded information about their ability to use the A SECRET framework to justify their choices and how they clinically reasoned through a complex client simulation. 


\section{METHODS}

This study was approved by a university Institutional Review Board.

\section{Participant Recruitment}

The participants were recruited through purposeful sampling among students in their third semester of their first year in an MOT program. A flyer overviewing the sequence of the study was sent to each potential participant. Twelve students responded to the email and were contacted by the researcher via face-to-face, phone, or email communication to verify they met the inclusion criteria, and to establish a time to review the study protocols. As a part of the initial steps of the study, each of the 12 participants signed the informed consent. Of these initial 12 participants, eight participants completed the entire study. The remaining four participants withdrew for various reasons (lack of time, poor time management, or semester workload issues).

Inclusion/exclusion criteria. Individuals who took part in this research study were required to: (a) be in his/her first year as an MOT student, (b) have not received formal education/instruction related to sensory processing disorders and A SECRET problem solving strategies, (c) have access to a computer with Internet access, (d) be able to complete the foundational instruction for sensory processing and SPDs via online modules from Sensory Processing Disorder University (SPDU), and (e) be able to complete the A SECRET instructional modules via the university learning management system during the designated two-week time frame.

\section{Brief Description of the Assessment Tool}

An assessment tool was designed by the primary author to determine if the students could discriminate between predetermined A SECRET reasoning strategies, following an online module about A SECRET (Gee et al., 2017). The assessment tool consisted of a developmental history and a video vignette of a pediatric client, Michael, who had challenging behaviors due to impaired sensory processing. The assessment was developed using the Delphi method with a group of experienced clinicians familiar with sensory processing disturbances and A SECRET. For each element of A SECRET (e.g., attention, sensation, etc.) six intervention strategies were listed. Those identified as appropriate by the group of experts were those that supported occupational performance and participation, aligned with the A SECRET reasoning process, and/or reduced negative behaviors related to sensory over-responsivity. Conversely, inappropriate strategies identified by the group of experts were the interventions that created barriers to occupational performance and participation, were not in alignment with the A SECRET reasoning process, and/or exacerbated negative behaviors related to sensory over-responsivity. Further information on the development of the instructional content and development and validation of the assessment tool referenced in this article can be found in other publications (Gee, 2015; Gee, Strickland, et al., 2017; Gee, Thompson, et al., 2017).

The resulting assessment tool consisted of an online quiz where participants had to read through a pre-determined list of six intervention strategies for each element of the A SECRET framework and rank each intervention (Gee, Thompson, et al., 2017). The 
intervention the participant identified as appropriate and the best choice for the clinical scenario was ranked as 1 , the intervention that was also appropriate but not the top/best choice was given a 2 . The interventions viewed as adequate were given a rank of a 3 or 4 and those identified as inappropriate for the clinical scenario were ranked as a 5 or a 6 (see Figure 1). Within the quiz, participants had to provide a written rationale for their rankings (see Figure 2).

\section{Figure 1}

\section{Sample Selected Response Rating of Strategy}

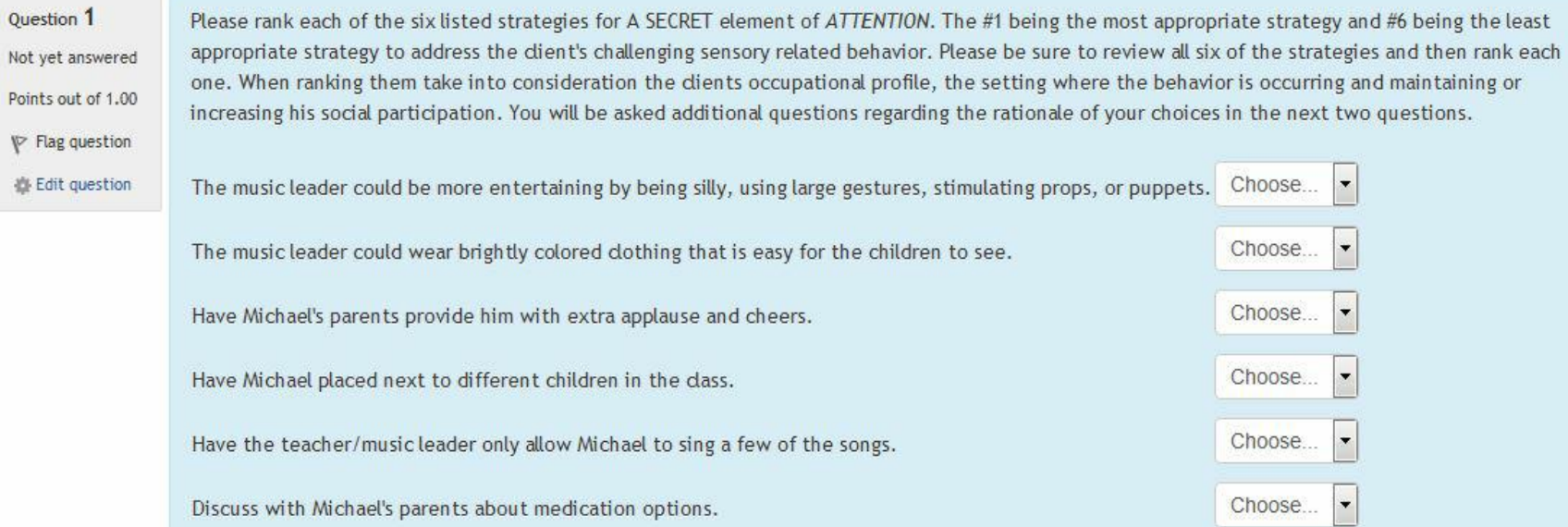

\section{Figure 2}

\section{Sample Strategy Rationale}

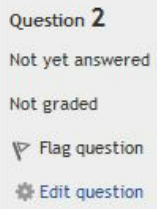




\section{Focus Group}

Following completion of the online course and assessment, participants took part in a 90-minute focus group with the researcher to elaborate on their experiences with the online course, assessment tool, and their rationales related to clinical reasoning. The focus group was conducted seven days after the participants had completed the A SECRET training modules. The focus group provided them with the opportunity to provide opinions regarding the A SECRET instruction, the online delivery of the content and additional reflections and analysis on their rationales and the A SECRET reasoning process. Using a semi structured interview guide (refer to appendix A), the focus group was audio recorded and later transcribed and analyzed as a part of the larger qualitative data obtained from the A SECRET case scenario assessment measure.

\section{DATA ANALYSIS}

The participants' written rationale for their rankings on the A SECRET assessment tool and qualitative data from the focus group transcript was used to describe how the participants clinically reasoned through the process of identifying appropriate or inappropriate interventions strategies. The process used with the qualitative analysis is sequenced below.

1. The student's original responses were exported from the learning management system used to deliver the online quiz and categorized by type (appropriate or inappropriate).

2. The researcher then read and re-read (Corbin \& Strauss, 2008) the transcribed responses from the focus group to create preliminary codes for both groupings of rationales (appropriate and inappropriate). The researcher used the following strategies to generate codes based upon Corbin and Strauss: "a) stimulate the inductive process, b) not taking the participants' statements for granted, and c) avoids rushing past the diamonds in the rough." (p. 67).

3. Once all the rationales had been coded by the researcher (Corbin \& Strauss, 2008), the initial codes and a word-processed document for each type (appropriate and inappropriate) were uploaded into a qualitative data analysis management system called DeDoose $\AA$.

4. Following this, the codes were further consolidated into categories by the researcher (Corbin \& Strauss, 2008). The categories represented broader groupings related to the reasoning behind the strategies ranked by the participants.

5. The researcher returned to the raw data in order to ensure it (original coded quotes) were represented by the newly created categories. The researcher reviewed and reorganized the categories based upon this additional review. 
6. From that point, the researcher sought to develop higher-level representations of the categories through generalized descriptive representations and sub representations to discover how the participants critically discriminated between the given A SECRET strategies deciding which were appropriate or inappropriate for application to the client in the case scenario.

7. The proposed descriptive representations were presented to the participants via a word-processed document for their review, comment, and possible modification. The participants made no clarifications or modifications related to the representation of their reasoning approach.

A total of 221 codes were ultimately developed and applied to the appropriate and/or inappropriate rationale statements. There were 95 codes applied to the rationales for the appropriate strategies and 126 codes for the inappropriate strategy rationales. This generated 145 excerpts, 79 among the rationales for inappropriate A SECRET intervention strategies and 66 excerpts for the appropriate A SECRET intervention strategies.

\section{RESULTS}

The participants of this study consisted of eight MOT students between the ages of 20 to 50 years, who were in the first 12 months of a three-year MOT program at a public university in the western United States. All the participants met the minimum criteria for admission into the MOT program and had a bachelor's degree in an associated area (University Studies, Psychology, Sociology, Exercise Science, etc.).

\section{Descriptive Representations from the Rationale Statements}

A total of five descriptive representations (themes) emerged from the qualitative data analysis of participant rationales and focus group. Figure 3 provides an illustration of the main descriptive representations and sub-representations (sub-themes) that characterized the participants' reasoning with regard to appropriate and inappropriate strategies. It does not reflect a hierarchy or relationship between the descriptive representations.

Each descriptive representation is discussed with an example of the raw qualitative data in the following paragraphs. For the sake of clarity, the majority of the quotes are taken directly from the rationale statements the participants submitted via the online quiz. There are occasions where quotes from the focus group are added and noted as such. These quotes were included in the analysis because of their value in adding depth to the written rationales, as well as giving strength to the descriptive representations. 
Figure 3

Appropriate/Inappropriate Rationale Descriptive Representations.

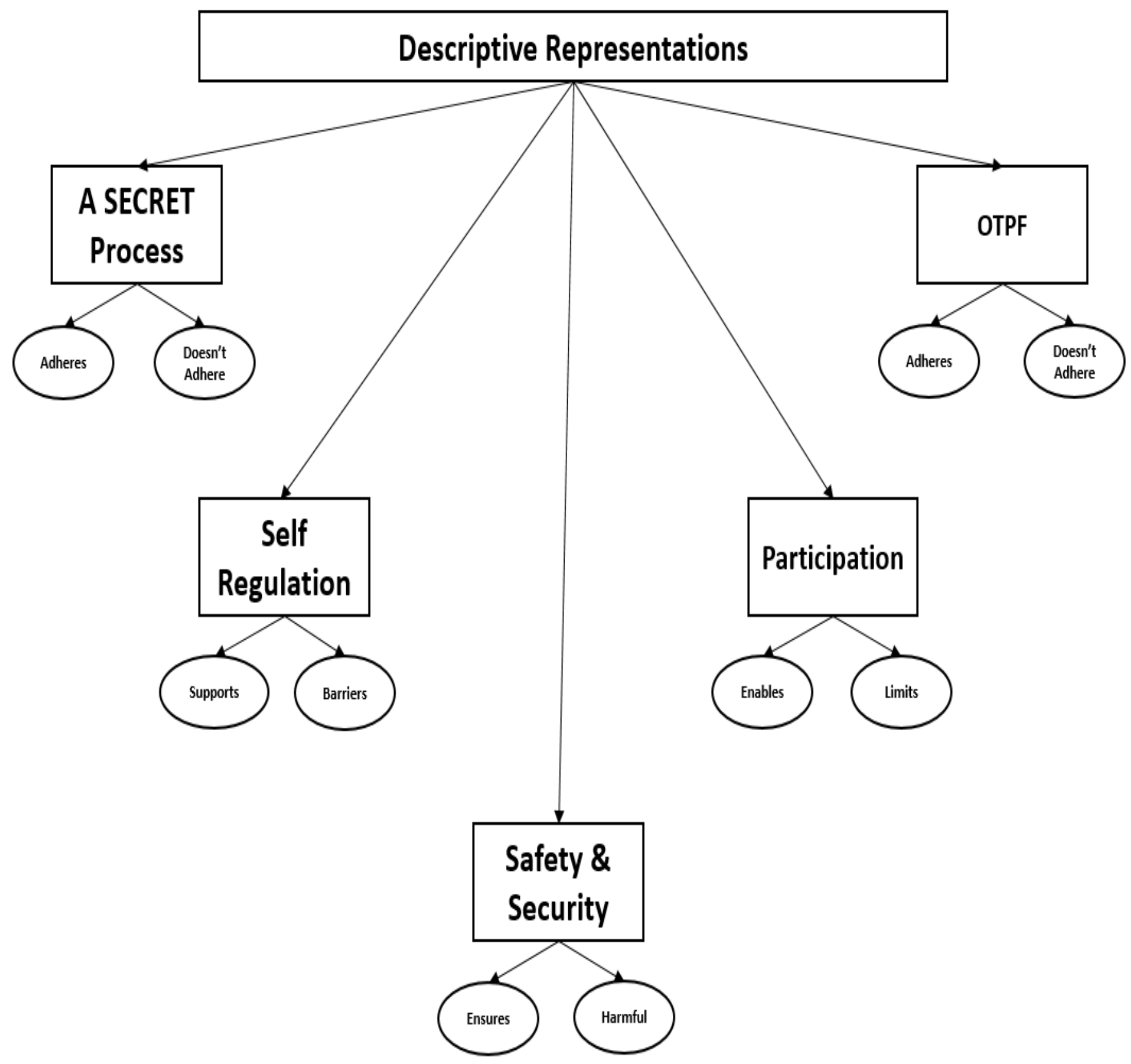

A SECRET process. This descriptive representation indicates how some of the participants used a rigid application of the A SECRET process taught within the instructional module, to determine the appropriate or inappropriate strategies. Participants' decisions were nuanced on whether or not the strategy adhered with the $A$ SECRET process based on a concrete application and their interpretation of the A SECRET process. 
Adheres. Details of this sub-representation included comments that related to how the pre-determined strategy adhered to the A SECRET procedure explicitly or indirectly. One participant articulated their opinion of a strategy via the goal of one of the six elements within A SECRET:

"The main goal of [the element] emotion regulation [within the A SECRET approach] is to help Michael to regulate his emotions when he is experiencing too much sensation. Talking about the program beforehand and providing suggestions for him to use in the moment is a good way for him to self soothe when feeling overwhelmed."

A similar rationale was provided by another participant related to addressing another element of A SECRET: "I also ranked providing fidget toys as a least appropriate strategy because it does not address the emotional regulation aspect as much as it would the sensory aspect (element) for Michael."

A statement from a participant during the focus group referred to the element of sensation: "Yeah, I just got done thinking back to the A SECRET videos, I mean, like what did they say worked best for sensation?"

An additional perspective was that the identified strategies that were deemed appropriate were more focused on the element in question: "I chose the first two strategies as the most appropriate for Emotional Regulation because they both help Michael to expect the sensory input that he will be faced with. They are the most focused on emotional regulation out of all the choices."

Finally, a participant connected a specific intervention with the element of attention: "I put the least effective at giving him more space to rock and spin, as this could be very distracting to other children and maybe embarrassing to the child. This rocking may also distract his attention [element of A SECRET] from the task he is supposed to be doing. Also, by playing on the playground... before the program may also heighten his senses too much... instead of calming him down depending on the stimuli he encounters while playing."

Doesn't adhere. Within the assessment tool there were several distractors that were created that did not align with the A SECRET instruction. The sub-representation of "Doesn't Adhere" captured the participants' rationales for ranking strategies lower, because the strategy did not support or adhere to the A SECRET process. One participant determined that a strategy was not appropriate because it did not fit categorically: "The third to last strategy is a sensation strategy rather than an emotional regulation strategy which is why I ranked it as sixth."

A second participant's thinking was similar, as it did not address the category of the case scenario question: "I also ranked providing fidget toys as a least appropriate strategy because it does not address the emotional regulation aspect as much as it would the sensation aspect for Michael." Another participant stated that the strategy needed to be aligned with the element in question: "Using a weighted blanket is more of 
a sensory diet item and could be distracting and cause him not to focus on the music. Providing more space is more of an environmental strategy than a sensation strategy."

One last rationale of note came from another participant who indicated the strategies ranked as inappropriate did not support the process or the issue in question: "Removing him from the program does not address the issue of A SECRET. He needs to participate with the help and direction given to him."

Self-regulation. This descriptive category involved the participants' recognition of the importance of self-regulation. Self-regulation included emotional regulation and the participants' opinions related to the opportunity for the client to learn how to selfregulate or the opportunity of others to teach the client how to self-regulate.

Supports. Participants selected strategies based upon their belief that the strategy would support the client's ability to self-regulate or attain the status of being emotionally regulated. A participant described why he/she ranked the strategy as 'appropriate' based upon the fact that it supported teaching self-regulation using the clients' caregivers to help him anticipate what would happen in the music program.

"The two I ranked the highest involved his parents making a plan for Michael during the music program. By assessing his arousal level prior to the concert, they could prepare him before he gets too overwhelmed. By talking to Michael directly about the music program, he is aware of what he should be doing at every part of the music concert."

Another participant also described how a strategy might help orient the client's attention to stay on task without eliciting problematic behaviors resulting from tactile and auditory sensory over-responsivity. Gaining and maintaining attention is a foundational cognitive skill needed to regulate oneself or one's emotions in spite of challenging or competing sensations within the context.

"I put that the teacher could be more animated or have puppets to gain attention. Since Michael is not over sensitive to visual stimuli as much as he is noises and tactile experiences, this could be a way to help gain his attention to stay on task without overwhelming his senses. Also, using visual stimuli could be for the teacher to wear brightly colored clothes, or something that will gain Michael's attention."

Barriers. The sub-representation of barriers may be described as the strategies the participants viewed as not supportive to the development of the client's self-regulation. One participant described how the strategies that he/she ranked as inappropriate were those that did not assist the client in controlling his emotions in a complex and sensory dynamic environment.

"Because Michael has problems with multi-senses having more songs with even bigger movements will further distract and disorganize how he handles the program. The songs already have a fair amount of movement in them and Michael does not do well with the noise and movement so having even more movement will most likely not help Michael to regulate his feeling of being overwhelmed. Having fidget toys may distract Michael even more from the program and will most likely not help him to control his feelings." 
A second participant articulated a rationale for the ranking of an inappropriate strategy based upon the fact that its focus either did not address the opportunity for the client to learn how to self-regulate or that it did not relate to regulation of any type:

"I ranked having Michael decide if he wants to participate as one of the least appropriate strategies because one of his goals is to increase social participation and if you just allow him to choose he might not get to learn and use those selfregulation tasks which could be used in the future even in a setting different from the school Christmas program. I also ranked providing fidget toys as a least appropriate strategy because it does not address the emotional regulation aspect as much as it would the sensory aspect for Michael."

Safety/security. The descriptive category of safety/security may best describe the rationales that were devised in relationship to the promotion of safety and security during the task within the contextual presentation of the case scenario. Some participants' rationales justified their rankings of strategies because they ensured the safety of the client and/or others within the context.

Ensures. Ensures is a sub-category that exemplified the participants' choice of strategy was based on the interpretation that the strategy would ensure the clients and others safety within the case scenario. One of the participants indicated they ranked a strategy as appropriate because it provided the client with both emotional safety and security. Specifically, this participant found the strategy could be implemented with discretion (to protect the client):

"I think the two most effective strategies would be for Michael to either sit by a preferred classmate or by an aid [sic] that could discreetly give him strategies for sensory input that he needs. By sitting by someone that he likes, Michael will feel more comfortable in the situation in general, and the aid [sic] could provide sensory input that he needs to stay on task."

During the focus group one participant shared that the basis for selecting a strategy was consideration of the client's feelings in response to the strategy.

"Just thinking about how he's, how he's going to feel if you separate him or don't involve him. He might already feel like a loner because everyone else around him is seeing it or whatever and listening and he's kind of in his own little world..."

During the same focus group, another participant explained she was more concerned of how the client would function in diverse and future contexts.

"Or even about how he's going to have to like he's going to have to be able to function in real life like, you know, he was, you know [sic], in elementary school for this program or whatever and what about, what happens when he gets to college and he has to, you know um, you know, maybe graduating or um, presentations-Like we have to do like um, I think that we have, you know, to think about how real, you know, real life context, and how it's going to affect him." 
Finally, a participant articulated a rationale that included ensuring social participation and discretion.

"I think putting Michael with students (preferably) that have a calming effect and imitate appropriate behavior will be best for him because it helps with social participation and also shows Michael how to imitate socially acceptable behavior (for social acceptance). My next choice would have a teacher/aid [sic] provide discrete cues to help him stay on task because he may need to be cued and we want that to be discrete."

Harmful. A few participants expressed concern regarding strategies that they viewed as having potential negative impact upon the client's sensory processing, participation, and overall wellbeing. Additionally, there were rationales where the participants' concerns extended beyond the client to other children. This is exemplified with one participant, who stated,

"The two least effective (strategies) would be to have the school cancel the music program, as this is unfair to the rest of the students that participate in it, as well as their parents. Also, by having him not participate, he may feel left out or 'different' then the rest of the students."

Another participant stated a similar rationale related to the potential harm a strategy might cause to the client and others:

"Having the school shorten the program is not an appropriate strategy because there are so many other children involved and probably traditions of which songs are included that it is probably not very rational to expect them to change everything just for Michael. Also, recommending to the school that they not do the program again is not a very appropriate strategy because the culture may necessitate a holiday program for parents/grandparents and eliminating the program entirely does not seem very feasible or reasonable."

Another participant stated a concern for how the strategy might have a negative impact upon the client's feelings during the context in question.

"The two least effective would be to place Michael by a child that is unpredictable or someone that he doesn't know. This may make him feel uncomfortable, which will heighten the other issues he will have during the music performance."

Yet another participant had a similar rationale related to harming the child or the group as a result of a poorly devised strategy.

"Having the school place noise cancelling boards through the auditorium is not a practical strategy because not many schools are going to be willing to pay the high cost for that, and it would affect the sound quality, which is what an auditorium is used for, and if the audience couldn't hear it would diminish the quality greatly."

Participation. Participation was a descriptive representation that was derived from the combination and rearrangement of several codes and categories that included occupational performance, meaningful activities and tasks, motivation, among others, 
within the present and future contexts for the client. The descriptive representation was divided into two sub-categories related to strategies that enabled participation and those that limited participation for the client.

Enables. This is a strategy that enabled opportunities for growth, access to affordances, and ways to learn to regulate oneself, socialize, and to enjoy the typical routines common with most children. One participant's rationale illustrates this subcategory by stating: "Having him sit next to a preferred classmate seems like the best option here because it allows him to be with a peer that could motivate and give him the right input (sensory)." Another participant argued that "tasks" would give the client more purpose during the music program and the activities presented within the video portion of the case scenario.

"Giving him more tasks to do is the most appropriate for this section because it will give him a job to do which distracts him from being bored. Hand gestures and body movements would be more entertaining for him than just singing, and would give him more participation in the program."

Another participant advocated for the use of predictability to enable participation of the client.

"Having Michael's parents talk to him prior to the program will provide more structure and predictability to the program. Also, by having the teacher provide a visual aid will help inform him what he needs to do, providing him with some structure and predictability in an unfamiliar setting."

Alternatively, a participant argued that reducing sensations would support attentiveness, which is foundational for increased participation in meaningful activities. "Decreasing tactile sensation may increase his focus on the program and not on the object. Allowing the children to get up and move will increase his attentiveness."

Finally, a participant articulated the idea of increasing support for participation in meaningful tasks in order to avoid social consequences.

"We've been like relating to um, like a social setting [sic], because by cancelling the play or having him in that concert like again, he's going to be, I guess different than other people even though like him being in that situation might be hard at first so I think it's important to learn techniques where he's able to not have that difference, you know, have that stereotype and so uh, that can relate to the social aspect."

Limits. This is a strategy that created a barrier for the client to remain stagnant with the sensory processing related behavioral challenges. One participant provided the following rationale, "Also sitting on a Disco-Sit $\AA_{B}$ may provide too much movement and stimulation where Michael will become over aroused by too much movement." An alternative perspective raised was that a strategy could be counterproductive to increasing attentiveness to the task at hand in the case scenario. "I also put giving him small, fidgety toys to play with as being less effective, because it will distract him from what he is supposed to be accomplishing." 
An additional view from a participant indicated a similar opinion.

"I think if all the kids were moving their bodies, it would be likely that Michael would start getting aroused and it would be hard for him to regulate his behavior after that initial arousal. He would start seeking more sensation after that initial arousal and it would be very distracting and frustrating. We also want Michael to take parts [sic] in these kinds of activities, so giving him a choice wouldn't be ideal, either."

Finally, another participant viewed the limitation to participation as having a cumulative effect upon the client sensory processing abilities.

"While it is unlikely that schools will stop doing music programs adding extra movements or walking to get the props would not be a good way to address ways to change the culture. Standing to get new props may cause Michael to be bumped in the hustle to get new props and that extra tactile input may do more harm. Also more movement may be more distracting to Michael and will potentially overload multiple senses."

The Occupational Therapy Practice Framework. The occupational therapy practice framework included the foundational tasks employed by occupational therapists to identify and document occupational performance deficits, analyze activities/tasks, develop intervention plans (including goals), intervention plan implementation, and reevaluation. This descriptive representation included two sub-categories in which the majority of the participants identified the client factors/process as being major influences upon their rationales.

Aligns with client factors/process. This descriptive representation captured the participants' justifications for the strategies they chose based upon alignment with the client factors and/or performance skills that are inherent influences on identifying occupational performance deficits and their impact upon function.

One participant articulated that using the client's strengths could help him overcome some of his sensory processing difficulties.

"Michael is not attending to the instructor and seems distracted, if the teacher could use humor, props or colors she might be able to get Michaels [sic] attention. One of Michael's moderate differences was visual, so he can use his strengths to overcome his deficits, which were his sensitivity to auditory sensations (the loud singing) from the children."

Another described the rationale for a specific strategy choice, because it would benefit the client based upon the client's sensory processing difficulties.

"I think when I was looking at the different ones to distract him (the client) like holding objects or doing other things I'm like well, his condition (sensory processing) is this something that would be beneficial so that's kind of why I chose that one [sic]." 
Similar examples exemplified the alignment of the client's sensory processing difficulty with how they were reasoning through the appropriate and inappropriate A SECRET strategies. The statements below originated from the focus group.

"And so I remember thinking about that in, and I actually talked about it in a lot of my paragraphs (rationales) about how we don't want to over stimulate him (the client) [sic] because it's going to lead to more adverse behaviors. As opposed to maybe if he gets all of this, you know, sensory input then he'll chill out, which in the videos it said that isn't the case for sensory seeking and so um, I felt like I had used what I learned based on what I had inferred his diagnosis to be."

"I thought about like was it having the parents clap louder um, I was like no [sic], that's not going to help like, that's adding to his stress like- In that instance I would have, you know, I thought back like okay, well, that's definitely not going to help him because of where he's at."

Doesn't support intervention goals. Participants described their opposition to some of the strategies, and rationale justifying their objections were rooted in how a given strategy did not support the client's goals presented within the developmental history. One participant linked a strategy to the client's goals to increase social participation: "Having him only participate for 25 minutes is a strategy that could be useful, but where one of his goals is to increase social participation I feel it would be more appropriate to look into changing other aspects before simply removing Michael from the program. That is also why I ranked having him sit in the audience as a least appropriate strategy because it does not allow him to work on selfregulating or social participation and so while it does change the task it changes it so much that he is no longer really participating."

Another participant justified the lower ranking of a strategy based upon the foundational goal of treatment and how the strategy did not align with the treatment plan (as represented in the A SECRET Case Scenario and Assessment instrument; Gee, Thompson, et al., 2017).

"Discussing Michael's medications may be appropriate in the initial assessment, but the goal of the treatment is for Michael to learn to identify and regulate his emotions. If Michael is able to sing or be a part of the concert, I wouldn't think it would be appropriate to only allow him to sing a certain number and then have him sit back."

Another participant was concise regarding how a strategy did not fit with the client's needs. "Removing Michael from the program would just be distracting and difficult for the parents and Michael and not actually address his needs."

The topic of medications came up several times in the rationales, and participants were concerned if prescribing medications was common practice among therapists or appropriate for children with this type of sensory processing difficulty. Below are two statements which were made during the focus group as the participants reflected upon the A SECRET strategy (in-appropriate) for the attention category portion from the assessment. 
"And on the first question I know it talked about medications. And I didn't know even how that played like if that is common to use with kids with SPD or not. But I figured that it was something that, I mean, [sic] would be kind of a last resort because you would want them to learn how to work through it."

"I feel like that's kind of contradicting like us [sic], I guess, like I think I wrote that, it was like my last one-or second to last one."

The participants used several types of strategies and underlying reasoning triggers that guided how they discriminated between strategies that were appropriate and inappropriate. The rationales they generated and the syntheses of such provides a glimpse into how first year MOT students reasoned through a static clinical problem and options.

\section{DISCUSSION}

In evaluating the qualitative findings, it was hypothesized that the participants directly or indirectly drew from three distinctly different areas of influence to support their rationales related to the appropriate and inappropriate A SECRET strategies (see figure 4); these influences included procedural, occupational therapy process, and learner specific. The strongest influence, procedural, was evident based upon the frequency of the responses from the participants that aligned with the materials presented within the online instructional modules. Participants made specific references to the content from the A SECRET process. This finding is similar to findings reported by Kramarski and Gutman (2006) who found that using enhanced online instruction increased the critical thinking skills via procedural application to solve complex mathematical problems. Conversely, Lysaght and Bent (2005) reported that live versus asynchronous occupational therapy case presentations did not affect students' ability to develop clinical reasoning skills based upon client factors or intervention. In our study, the MOT students consistently referred back to the online modules. How these students learned the A SECRET reasoning process supports the idea of using online modules and the assessment tool to teach and evaluate clinical reasoning, and there is emerging support from the literature aligning with this type of instructional delivery.

The second area influencing participants' clinical reasoning came from the occupational therapy process, which likely originated from the prior instruction within the curriculum. It is our assumption that in the event that the participants were unable to draw from the content of the A SECRET online training, they applied what they had learned from foundational occupational therapy coursework. Content presented in the curriculum related to activity analysis and the occupational therapy process description from the Occupational Therapy Practice Framework (OTPF) (AOTA, 2014). Further research is warranted to understand how prerequisite content influences the clinical reasoning process among occupational therapy students.

The final influence, specific to the learner, seemed to be based upon the participants' individual cultural, moral, and/or ethical views. Though more difficult to extrapolate, participants evaluated A SECRET strategies to determine if they were fair to the client in 
question or the other children within the case scenario. Unsworth (2004) concluded that participants' (occupational therapists) personal motivations, values and beliefs influenced their clinical reasoning within pragmatic reasoning. In another study, Hooper (1997) reported that occupational therapists' worldviews influence how therapists reasoned through clinical challenges. Our findings that the participants in this study rationalized their ratings based upon whether a strategy would ensure the client's emotional safety and wellbeing align with previous literature on clinical reasoning. Overall, it may be assumed, when lacking procedures or intervention knowledge students will fall back upon their own ethical/moral guides as a part of clinical reasoning, yet further research is warranted in this area.

Figure 4

Factors Influencing Descriptive Representations

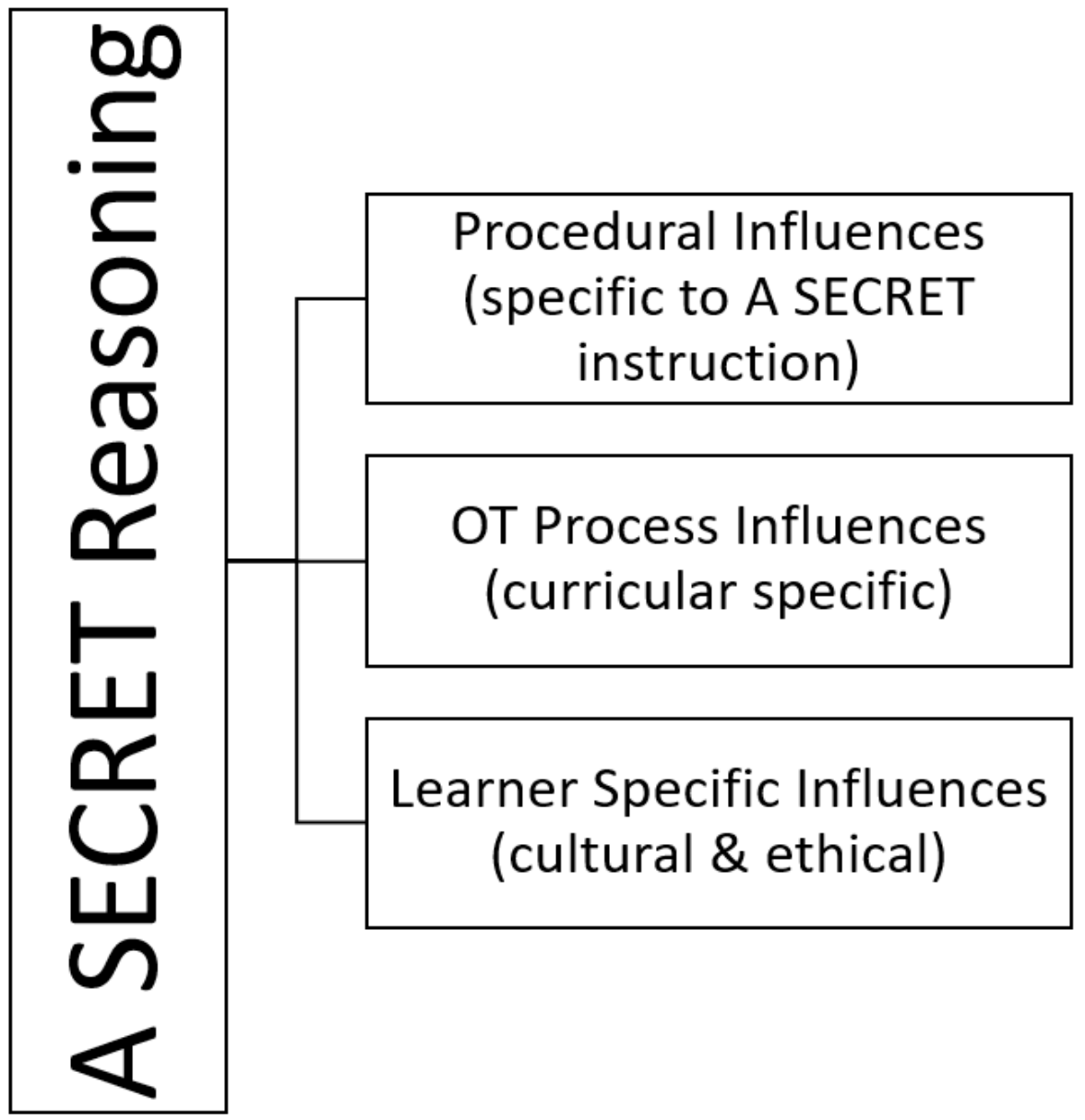




\section{Implications for Educators}

The findings from this study lend support towards the expectation that students immediately integrated the instructional content as they engaged in a case simulation instructional activity. Of note, three key findings may contribute to the training of entrylevel occupational therapists. First, educators must recognize that procedural and conditional reasoning skills may be developed during a student's foundational year, prior to increased instruction related to conditions and interventions. Second, online delivery of novel content may positively influence the clinical reasoning of first year occupational therapy students which may augment more formal didactic course instruction. Finally, embedding options that require students to provide justifications of decisions as a part of selected response assessments can provide a valuable window to the type of reasoning employed by first year students.

\section{Limitations}

Given that this study was a case study it is difficult to generalize the findings to the broader population of occupational therapy graduate students. Additionally, the small sample size contributes to the inability to generalize as well. There are very few scenarios where students or therapists are limited to examinations with text boxes to describe their rationale of certain interventions as a part of summative evaluation. Thus, our study's 'Case Scenario Assessment' process may not represent the optimal conditions to generate and evaluate students' clinical reasoning either in the moment or retrospectively.

\section{Recommendations for Future Research}

Future research could explore the difference in critical thinking and clinical reasoning among first and third year occupational therapy students as they apply a specific clinical technique or procedure as a part of a case simulation. It is recommended that additional research be conducted using the same instructional content and form of delivery, but in a manner that permits a larger sample size and includes the use of control and experimental groups. The above mentioned design recommendations could be accomplished using MOT students enrolled in their first year from a source academic institution as well as students from larger academic institutions. Another form of inquiry could include the comparison of participant performance during a stand-alone instructional activity (as it was in this study) versus those who had the module imbedded within a formal course relevant to the A SECRET process (e.g., pediatrics, mental health) could also be examined.

\section{References}

American Occupational Therapy Association. (2010). 2010 Occupational Therapy Compensation and Workforce Study. AOTA Press, Bethesda, Maryland.

American Occupational Therapy Association. (2012). 2011 Accreditation Council for Occupational Therapy Education (ACOTE®) Standards. American Journal of Occupational Therapy, 66(6_Supplement):S6-S74. doi: 10.5014/ajot.2012.66S6.

American Occupational Therapy Association. (2014). Occupational therapy practice framework: Domain and process (3rd Edition). American Journal of Occupational Therapy, 68(Supplement_1): S1-S48. doi:0.5014/ajot.2014.682006. 
Bailer, D. S., \& Miller, L. J. (2011). No longer a secret: Unique common sense strategies for children with sensory or motor challenges. Arlington, TX: Sensory World.

Coker, P. (2010). Effects of an experiential learning program on the clinical reasoning and critical thinking skills of occupational therapy students. Journal of Allied Health, 39(4), 280-286.

Cole, M. B., \& Tufano, R. (2008). Applied theories in occupational therapy: A practical approach. Thorofare, NJ: Slack.

Corbin, J., \& Strauss, A. (2008). Basics of qualitative research: Techniques and procedures for developing grounded theory (3rd ed.). Thousand Oaks, CA: Sage.

Crabtree, J. L. (1998). The end of occupational therapy. American Journal of Occupational Therapy, 52(3), 205-214. doi:10.5014/ajot.52.3.205

Creel, T. (2001). Chat rooms and level II fieldwork. Occupational Therapy in Health Care, 14, 55-59. doi.10.1080/J003v14n02_03

Gee, B. (2015). Exploring the effectiveness of an e-learning module for graduate level first year occupational therapy students. Unpublished Dissertation, Idaho State University, Pocatello, Idaho, USA.

Gee, B. M., Strickland, J., Thompson, K., \& Miller, L. J. (2017). Exploring the influence of an e-learning sensory processing-based module for graduate level occupational therapy students on clinical reasoning: A pilot study. Occupational Therapy International, Article ID 6515084, 8 pages. doi:10.1155/2017/6515084

Gee, B. M., Thompson, K., Strickland, J., \& Miller, L. J. (2017). The development of a measurement tool evaluating knowledge related to sensory processing among graduate occupational therapy students: A process description. Occupational Therapy International, Article ID 6713012, 7 pages. doi:10.1155/2017/6713012

Green, V. A., Pituch, K. A., Itchon, J., Choi, A., O'Reilly, M., \& Sigafoos, J. (2006). Internet survey of treatments used by parents of children with autism. Research in Developmental Disabilities, 27(1), 70-84. doi:10.1016/j.ridd.2004.12.002

Harries, P. A., \& Harries, C. (2001). Studying clinical reasoning, part 1: Have we been taking the wrong track? British Journal of Occupational Therapy, 64(4), 164-168. doi.10.1177/030802260106400402

Hedge, N., Pickens, N., \& Neville, M. (2015). A model of clinical reasoning: What students learn from patient educators. American Journal of Occupational Therapy, 69, doi:10.5014/ajot.2015.69S1-PO4082

Higgs, J., \& Jones, M. A. (2008). Clinical decision making and multiple problem spaces. In J. Higgs, M. Jones, S. Loftus, \& N. Christensen (Eds.), Clinical reasoning in the health professions ( $3^{\text {rd }}$ ed., pp. 3-17). New York: Elsevier.

Hooper, B. (1997). The relationship between pre-theoretical assumptions and clinical reasoning. American Journal of Occupational Therapy, 51, 328-338. doi:10.5014/ajot.51.5.328

Lysaght, R., \& Bent, M. (2005). A comparative analysis of case presentation modalities used in clinical reasoning coursework in occupational therapy. American Journal of Occupational Therapy, 59, 314-324. doi:10.5014/ajot.59.3.314

Kramarski, B., \& Gutman, M. (2006). How can self-regulated learning be supported in mathematical E-learning environments? Journal of Computer Assisted Learning, 22(1), 24-33. doi: 10.1111/j.1365-2729.2006.00157 
Mattingly, C., \& Fleming, M. H. (1994). Clinical reasoning: Forms of inquiry in a therapeutic practice. Philadelphia: FA Davis.

Miller, L. J., Fuller, D. A., \& Roetenberg, J. (2014). Sensational kids: Hope and help for children with sensory processing disorder (SPD). England: Penguin.

Miller, L. J., Reisman, J. E., McIntosh, D. N., \& Simon, J. (2001). An ecological model of sensory modulation: Performance of children with fragile $\mathrm{X}$ syndrome, autistic disorder, attention-deficit/hyperactivity disorder, and sensory modulation dysfunction. Understanding the nature of sensory integration with diverse populations, Arizona: Therapy Skill Builders.

Murphy, E. (2004). An instrument to support thinking critically about critical thinking in online asynchronous discussions. Australian Journal of Educational Technology, 20, 295-318. doi.10.14742/ajet.1349

Neistadt, M. (1996). Teaching strategies for the development of clinical reasoning. American Journal of Occupational Therapy, 50, 676-684. doi:10.5014/ajot.50.8.676

Neistadt, M., Wight, J., \& Mulligan, S. (1998). Clinical reasoning case studies as teaching tools. American Journal of Occupational Therapy, 52, 125-132. doi:10.5014/ajot.52.2.125

Owen, J. P., Marco, E. J., Desai, S., Fourie, E., Harris, J., Hill, S. S., Arnett, A. \& Mukherjee, P. (2013). Abnormal white matter microstructure in children with sensory processing disorders. Neuroimage: Clinical, 2, 844-853. doi.10.1016/j.nicl.2013.06.009

Peloquin, S. M., \& Davidson, D. A. (1993). Interpersonal skills for practice: An elective course. American Journal of Occupational Therapy, 47(3), 260. doi:10.5014/ajot.47.3.260

Reynolds, S., Watling, R., Zapletal, A.L, \& May-Benson, T. (2012). Sensory integration in entry-level occupational therapy education. Sensory Integration Special Interest Section Quarterly Newsletter, 35(4), 1-4.

Rogers, J. C. (1983). Eleanor Clarke Slagle Lectureship_1983; Clinical reasoning: the ethics, science, and art. American Journal of Occupational Therapy, 37(9), 601616. doi:10.5014/ajot.37.9.601

Scaffa, M., \& Wooster, D. (2004). Effects of problem-based learning on clinical reasoning in occupational therapy. American Journal of Occupational Therapy, 58, 333-336. doi:10.5014/ajot.58.3.333

Scanlan, J. N., \& Hancock, N. (2010). Online discussions develop students' clinical reasoning skills during fieldwork. Australian Occupational Therapy Journal, 57(6), 401-408. 10.1111/j.1440-1630.2010.00883.x

Schell, B., \& Schell, J. (2008). Clinical and professional reasoning in occupational therapy. Baltimore, MD: Wolters Kluwer.

Tickle-Degnen, L. (2000). Gathering research evidence to enhance clinical reasoning. American Journal of Occupational Therapy, 54, 102-105. doi:10.5014/ajot.54.1.102

Thomas, A. \& Storr, C. (2005). WebCT in occupational therapy clinical education: Implementing and evaluating a tool for peer learning and interaction. Occupational Therapy International, 12, 162-179. doi: 10.1002/oti.3 
Tomchek, S. D., Huebner, R. A., \& Dunn, W. (2014). Patterns of sensory processing in children with an autism spectrum disorder. Research in Autism Spectrum Disorders, 8(9), 1214-1224. doi.10.1016/j.rasd.2014.06.006

Trujillo, L. \& Painter, J. (2009). The effectiveness of discussion board usage for occupational therapy fieldwork II students. Journal of the Research Center for Educational Technology, 5, 80-88.

Unsworth, C. A. (2004). Clinical reasoning: How do pragmatic reasoning, worldview and client- centredness fit? British Journal of Occupational Therapy, 67(1), 10-19. doi:10.1177/030802260406700103

Wickremasinghe, A. C., Rogers, E. E., Johnson, B. C., Shen, A., Barkovich, A. J., \& Marco, E. J. (2013). Children born prematurely have atypical sensory profiles. Journal of Perinatology, 33(8), 631-635. doi:10.1038/jp.2013.12

Wooster, D. (2004). An exploratory study of web-based supports for occupational therapy students during level II fieldwork. Occupational Therapy in Health Care, 18, 21-29. doi.10.1080/J003v18n01_03 


\section{Appendix A Semi Structured Interview Guide for Focused Group}

Greetings, in the first portion of our discussion, I will ask you questions that relate to the instruction you took part in through the Sensory Processing Disorder University or SPDU. Specifically, we will discuss the assessment activities and the content presented through Idaho State University and the Sensory Processing Disorder University.

\section{Part 1: Questions related to SPDU e-learning assessment and content.}

SPDU Content

1. Did the sequence of SPDU modules support your increased understanding of SPD and the associated SPD strategies and interventions?

a. What did you prefer regarding the sequence of modules?

b. What would you change regarding the sequence modules?

2. What were the specific modules of the SPDU that assisted you with generating $A$ SECRET strategies to address the sensory related behavioral challenges within the case scenario at the end of the A SECRET instructional lessons?

3. What specific factors were missing from the SPDU modules that would have assisted you with the generation of A SECRET strategies to address the sensory related behavioral challenges in the case scenario at the end of the instructional modules?

\section{SPDU Pre Treatment Assessment}

4. What are your opinions of the SPDU Assessment procedure that you took part in at the end of the SPDU instructional modules?
a. How many of you think that they were appropriately matched with the objectives of the modules?
b. How many of you thought that they were inappropriately matched?

\section{Part 2: ISU A SECRET Instructional Experience Interface}

5. Let's discuss your overall impressions of the following portions of the A SECRET lessons?

a. In what ways did the audio support your learning?

b. How did the quality of the video reinforce the topics presented?

1. In what ways did the clinician vignette within each A SECRET lesson support your understanding of the elements or steps of $A$ SECRET?

2. In what ways did the parent interview vignette within each $A$ SECRET lesson support your understanding of the A SECRET process? 
6. In general, which categories of A SECRET strategies were easier for you to understand and apply:
a. $\quad$ the individual characteristics (attention, sensation \& emotional regulation)?
b. the contextual elements (culture, relationships, environment, tasks)?

\section{Instructional Delivery}

7. By the show of hands how many of you preferred to have instruction delivered in an online format?
a. Why did you prefer the online format?
b. For those who did not prefer the content delivered in the online format, why?
c. Would you prefer to have additional content related to this topic or other occupational therapy topics in an online format?

8. What additional information or instructional activities would have helped you understand the A SECRET elements better?

ISU A SECRET Assessment

9. What are your opinions of the ISU A SECRET case scenario assessment procedure that you took part in at the end of the A SECRET instructional lessons?
a. What are your opinions of not having a chance to go back and review the scenario during the assessment?

10. Did you have enough information from the ISU A SECRET module to generate strategies that you felt adequately address the sensory related behavioral challenge?
a. What information assisted you in the case scenario?
b. What information would you have liked to have included in the A SECRET lessons?

11. What specific factors were missing from the ISU A SECRET module that would have assisted you with the generation of A SECRET strategies to address the sensory related behavioral challenges in the case scenario at the end of the instructional lessons?

12. What were the general influences (external to the ISU A SECRET lessons) for the A SECRET strategies you generated based upon the case scenario?
a. How did you determine which of the 6 strategies were the most appropriate for the given element of A SECRET?
b. How did you determine which of the 6 strategies were the least appropriate for the given element of A SECRET?


c. Were the influences based upon the instruction you may have received prior to the study? If so what were they?

1. Occupational therapy coursework

2. Clinical observations (preprogram admission observations or Level I)?

3. Other print materials?

4. Other electronic resources?

d. Were the influences based upon the instruction you took part in via the Sensory Processing Disorder University as a part of the study? If so what were they?

e. Were the influences based upon the A SECRET instructional modules as a part of the study? If so what were they?

13. I have provided you with a list and definitions of different types of clinical reasoning approaches that occupational therapists use as a part of clinical practice (see handout).

a. $\quad$ By the show of hands how many of you used procedural clinical reasoning?

b. By the show of hands how many of you used narrative clinical reasoning?

c. By the show of hands how many of you used pragmatic clinical reasoning?

d. By the show of hands how many of you used narrative clinical reasoning?

e. Those of you who used procedural clinical reasoning, how do you believed you used it?

f. Those of you who used narrative clinical reasoning, how do you believed you used it?

g. Those of you who used pragmatic clinical reasoning, how do you believed you used it?

h. Those of you who used narrative clinical reasoning, how do you believed you used it? 